\title{
Short-latency somatosensory evoked potentials in degenerative and vascular dementia
}

\author{
G ABBRUZZESE, L RENI, L COCITO, S RATTO, M ABBRUZZESE AND E FAVALE \\ From the Department of Neurology, University of Genoa, Italy
}

SUMMARY Short-latency somatosensory evoked potentials (SEPs) were recorded from 54 patients with dementia as compared to 32 age-matched controls. SEPs were generally normal in patients with senile dementia of Alzheimer type, while patients with multi-infarct dementia showed a prolonged central conduction time, an increased latency of both N13 and N20 and a reduction of the primary cortical response amplitude. These findings suggest that recording SEPs may be useful in the differential diagnosis between degenerative dementia and multi-infarct dementia.

Dementia may be regarded as a clinical syndrome caused by many widespread destructive conditions of the brain, the most frequently observed types being the senile dementia of the Alzheimer type, the so called multi-infarct dementia and the mixed forms of dementia. ${ }^{2}$ All these conditions can be associated with pathological changes of the neural structures mediating the somatosensory evoked potential (SEP). We report here the short-latency SEP findings in 54 patients affected by dementia as compared to 32 age-matched controls to show that SEP abnormalities occurring in dementia may represent a useful tool in the differential diagnosis between senile dementia of the Alzheimer type and multi-infarct dementia.

\section{Material and methods}

The study was performed in 54 patients with dementia ( 32 females and 22 males; aged $42-82$, mean 67.4 years; mean height $159.7 \mathrm{~cm}$ ) and in 32 age-matched normal controls (15 females and 17 males; aged $49-82$, mean 65.8 years; mean height $166.8 \mathrm{~cm}$ ). Patients entering this study were considered demented on the basis of history, clinical features, psychometric evaluation (WAIS and Wechsler Memory tests, Benton test, Color Naming) ${ }^{3}$ and the results of routine blood, electrophysiological and radiological examinations, including computed tomography (CT). Five

Address for reprint requests: Giovanni Abbruzzese, MD Clinica Neurologica dell'Università, Via De Toni, 5, I 16132 Genova, Italy

Received 31 January 1984

Accepted 10 March 1984 patients were not included in the study since they had a pathologically decreased sensory conduction velocity of $\stackrel{\mathbb{D}}{\vec{D}}$ 을 the median nerve. According to the Hachinski Ischemic $\stackrel{\rho}{\stackrel{\rho}{1}}$ Score $^{4}$ patients were classified as: 1 . senile dementia of the $\stackrel{\mathbb{D}}{2} \overrightarrow{-}$ Alzheimer type, 30 cases (55.6\%), 2. multi-infarct demen- $\sigma$ tia, 18 cases $(33.3 \%)$, 3. mixed forms of dementia, six cases $(11 \cdot 1 \%)$. Thirty two patients, admitted to the Department of Ophthalmology of the University of Genoa because of cataract or glaucoma, consented to serve in this study as normal controls. They all had neurologic examination, psychometric evaluation and median nerve sensory conduction velocity determination in the normal range.

Cortical and cervical somatosensory responses evoked by median nerve stimulation at the wrist (frequency: $1 \mathrm{~Hz}$; intensity: thumb motor threshold) were recorded from an active electrode, placed respectively over the somatosensory cortical hand area and between the second and third cervical spines, with a midfrontal reference. The amplifier bandpass was from 16 to $5000 \mathrm{~Hz}$. and usually 512 responses were averaged over $50 \mathrm{~ms}$ with an artefact reject facility. Stimulation, recording and averaging techniques have been extensively described elsewhere. ${ }^{5}$

The following parameters were investigated: (a.) amplitude and latency of the main negative peak (N13) of the cervical response and of the first main negative peak (N20) of the cortical response (in both cases amplitude was measured with reference to the following peak of opposite polarity); (b.) the central conduction time (CCT), that is the difference between the actual latencies of N20 and N13. Amplitude values of both sides were at first submitted to a log transformation and for each subject the mean of the left and right log values was considered. ${ }^{6}$ Amplitude mean values of normals and demented patients were statistically compared by the analysis of variance. ${ }^{7}$

The mean N13 and N20 latency values of left and right 

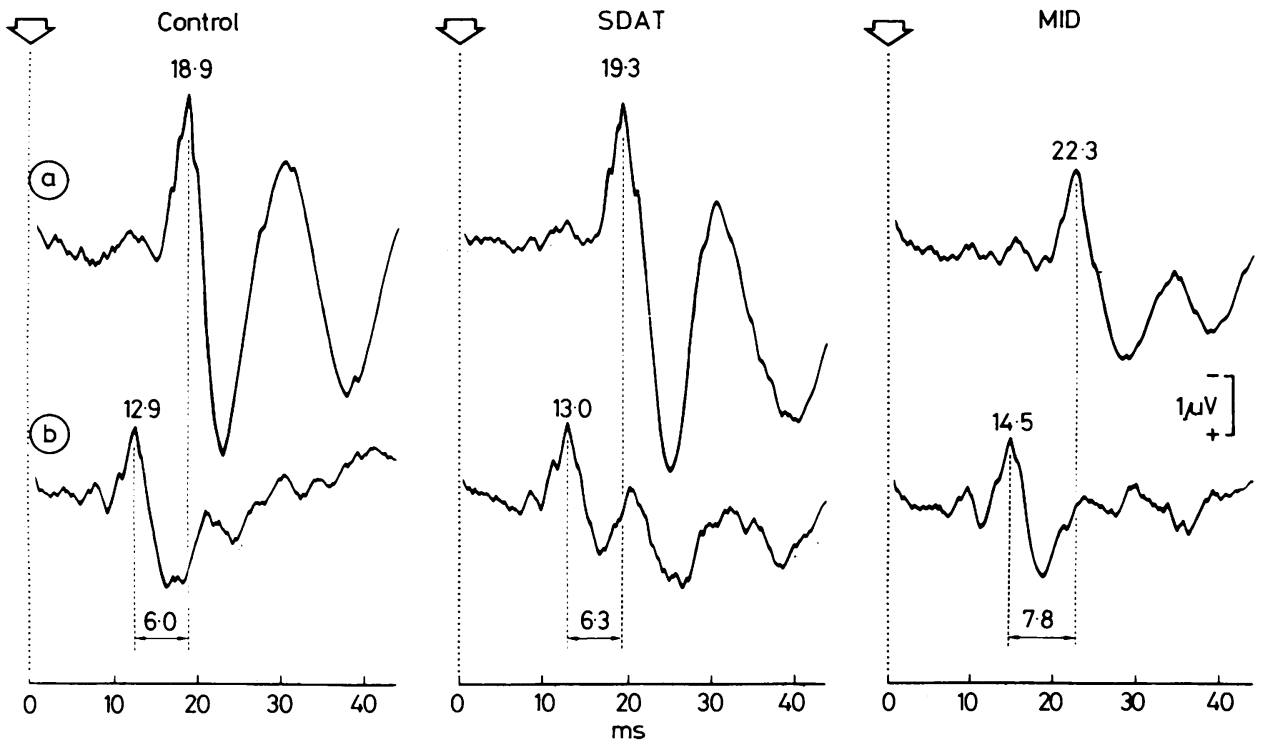

Fig Cortical $(A)$ and cervical $(B)$ somatosensory responses evoked by median nerve stimulation at the wrist in a normal control (left), a senile dementia of the Alzheimer type patient (centre) and a multi-infarct dementia patient (right), of the same height $(160 \mathrm{~cm})$, aged 69, 69 and 72 years respectively. The actual $N 13$ and N20 latencies and the CCT values are indicated. SEPs of multi-infarct dementia patient are characterised by a delayed latency of both $\mathrm{N} 13$ and N20, a prolonged CCT and a reduction of the primary cortical response amplitude.

sides were considered unless a large asymmetry (greater than $0.7 \mathrm{~ms}$ for $\mathrm{N} 13$ and than $1.0 \mathrm{~ms}$ for $\mathrm{N} 20)^{6}$ was present; in this case, the values of the side with a longer latency were considered. A comparison between latency values of normals and demented patients was made by a univariate analysis of covariance, ? in order to remove the obvious effect of the length of the pathway on conduction time. ${ }^{8}$ In contrast, the CCT of normals and demented patients, being unrelated to the height of the subjects, ${ }^{8}$ was compared by the analysis of variance. For each SEP parameter the upper and lower confidence limits were determined as: mean \pm $2 \cdot 5 \mathrm{SD}$ of normal controls.

\section{Results}

The results of the study are summarised in the table and typical examples of SEPs in normal controls and demented patients are shown in the figure.

Degenerative dementia. Senile dementia of the Alzheimer type patients were not different from controls for any of the SEP parameters under investigation. Only one patient exceeded the upper confidence limit of normal population for both N20 latency CCT. The N20 amplitude was under the

Table SEP latencies and amplitudes of controls and demented patients (mean \pm SD)

\begin{tabular}{|c|c|c|c|c|}
\hline & Controls & $\begin{array}{l}\text { Senile dementia of } \\
\text { the Alzheimer type }\end{array}$ & $\begin{array}{l}\text { Multi-infarct } \\
\text { dementia }\end{array}$ & $\begin{array}{l}\text { Mixed forms of } \\
\text { dementia }\end{array}$ \\
\hline $\begin{array}{l}\text { N13 Latency* (ms) } \\
\text { N20 Latency* (ms) } \\
\text { CCT }\end{array}$ & $\begin{array}{c}12.99 \pm 0.59 \\
(13.32 \pm 0.68) \\
18.89 \pm 0.63 \\
(19.17 \pm 0.70) \\
5.85 \pm 0.45\end{array}$ & $\begin{array}{c}13.24 \pm 0.69 \\
(12.89 \pm 1.02) \\
19.32 \pm 0.79 \\
(19.03 \pm 0.98) \\
6.11 \pm 0.50\end{array}$ & $\begin{array}{c}13.84 \pm 0.58 \\
(13.82 \pm 1.03) \\
20.59 \pm 1.05 \\
(20.58 \pm 1.21) \\
6.75 \pm 0.86\end{array}$ & $\begin{array}{c}14.05 \pm 0.96 \\
(13.9 \pm 0.77) \\
20.18 \pm 1.21 \\
(20.05 \pm 0.76) \\
6.15 \pm 0.50\end{array}$ \\
\hline $\begin{array}{l}\text { N13 Amplitude } \dagger(\mu \mathrm{V}) \\
\text { N20 Amplitude } \dagger(\mu \mathrm{V})\end{array}$ & $\begin{array}{l}0.290 \pm 0.13 \\
(2.03 \pm 0.60) \\
0.692 \pm 0.14 \\
(5.15 \pm 1.51)\end{array}$ & $\begin{array}{l}0.242 \pm 0.12 \\
(1.81 \pm 0.49) \\
0.660 \pm 0.25 \\
(5.31 \pm 2.78)\end{array}$ & $\begin{array}{l}0.230 \pm 0.14 \\
(1.79 \pm 0.59) \\
0.492 \pm 0.27 \\
(3.59 \pm 1.73)\end{array}$ & $\begin{array}{l}0.185 \pm 0.10 \\
(1.57 \pm 0.34) \\
0.614 \pm 0.18 \\
(4.41 \pm 1.70)\end{array}$ \\
\hline
\end{tabular}

* The height-covariated latencies are reported (between brackets the actual values).

†Amplitudes are expressed as log units (between brackets the actual values). 
lower confidence limit in three subjects and over the upper confidence limit in one subject.

Vascular dementia. The mean N13 latency of multiinfarct dementia patients was increased as compared to either senile dementia of the Alzheimer type patients $(F=8.49, p<0.005)$ or controls $(F=$ $17 \cdot 49, \mathrm{p}<0.001)$. Four patients exceeded the upper confidence limit for N13 latency. No difference of N13 mean amplitude was observed. The N20 mean latency was increased as compared to either senile dementia of the Alzheimer type patients $(F=27 \cdot 45$, $p<0.001)$ or controls $(F=50.64, p<0.001)$ and 11 patients exceeded the upper confidence limit. The mean amplitude of the primary cortical response was reduced in multi-infarct dementia patients as compared to either senile dementia of the Alzheimer type patients $(F=6.58, p<0.025)$ or controls $(F=9 \cdot 50, p<0.005)$ and three patients showed an amplitude value under the lower confidence limit of normal population.

The mean CCT of multi-infarct dementia patients was increased as compared to either senile dementia of the Alzheimer type patients $(F=13 \cdot 55, p<$ $0.001)$ or controls $(F=27.08, p<0.001)$, seven patients exceeding the upper confidence limit.

Overall, 12 multi-infarct dementia patients out of $18(66.6 \%)$ showed an abnormal SEP for at least one of the considered parameters, most frequently N20 and/or CCT.

Mixed forms of dementia The mean values of this group were not statistically analysed since the sample was too small. Three patients exceeded the upper confidence limit for N20, N13 CCT.

$C T$ findings. The CT examination showed signs of cerebral atrophy (ventricular enlargement and/or widening of the sulci) in 27 out of 30 senile dementia of the Alzheimer type patients. Isolated or multiple areas of reduced density attributable to ischaemic lesion(s) were observed in the CT of 15 out of 18 multi-infarct dementia patients and only in four out of 30 senile dementia of the Alzheimer type patients; a significant relationship between the occurrence of SEP abnormalities and of focal ischaemic brain lesion(s) was present $\left(\chi^{2}=4 \cdot 13, p\right.$ $<0.05)$. Such relation, however, cannot be regarded as absolute since 3 multi-infarct dementia patients showed SEP abnormalities without any evidence of CT focal lesions, while six multi-infarct dementia patients and three senile dementia of the Alzheimer type patients presented ischaemic lesions but completely normal SEPs.

\section{Discussion}

Short-latency SEPs are fairly normal in patients with degenerative dementia while they are frequently altered in patients with vascular dementia, showing a prolonged CCT, an increase of the heightcovariated latency of both $\mathrm{N} 13$ and N20 and a reduction in the amplitude of the primary cortical response.

The occurrence in senile dementia of the Alzheimer type of the same SEP features currently observed in normal aging ${ }^{10}$ is apparently in contrast with the widespread cortical atrophy typically observed in degenerative dementia " and cannot be easily explained, unless compensatory plasticity of the spared cortical cells be postulated. On the contrary, the frequent occurrence of SEP abnormalities in multi-infarct dementia patients is not surprising since the majority of lesions are placed in the hemispheric subcortical white matter, leaving the cortex for the most part intact. " These lesions can imply a damage to the central SEP pathway leading to a reduced amplitude and a delayed onset of the cortical primary response or to a prolonged CCT, as in the case of patients with focal disorders of the brainstem or thalamus. ${ }^{12}$

These findings suggest that cortical neuron loss may be less relevant to the occurrence of short latency SEP abnormalities than subcortical axon destruction, this latter producing a greater functional impairment. In this regard it should be pointed out that we observed similar SEP changes in three patients (not included in this study) with Huntington's disease (see also Josiassen et al. ), ${ }^{13}$ which is characterised by a widespread subcortical atrophy with less dramatic cortical changes."

Although N20 turned out to be the most sensitive parameter (as already suggested in a previous study), ${ }^{6}$ the CCT, being unrelated to the height of the subjects and usually unaffected by any condition causing a slowing of peripheral conduction velocity, is a more practical diagnostic index. The surprising observation of an increased N13 latency in multiinfarct dementia patients might reflect the occurrence of a posterior tract damage in chronic spinal ischaemia, ${ }^{14}$ concealed by the general vascular disease. Such finding, however, is unlikely to be diagnostically useful because of the great overlap between the groups.

SEP abnormalities were obviously more frequent in patients with CT evidence of focal brain lesion(s), but clear-cut alterations could be recorded even in the absence of visible CT focal changes.

The differential diagnosis between degenerative and vascular dement $A$ still represents a difficult clinical problem. ${ }^{2}$ Our results suggest that recording SEPs in demented patients can be helpful, even when scoring evaluation or CT are not discriminant. 


\section{References}

' Small GW, Jarvik LF. The dementia syndrome. Lancet 1982:ii: 1443-5.

${ }^{2}$ Loeb C, Gandolfo C. Diagnostic evaluation of degenerative and vascular dementia. Stroke 1983;14:399-401.

${ }^{3}$ Wells CE, Buchanan DC. The clinical use of phychological testing in evaluation for dementia. In: Wells CE. ed. Dementia. Philadelphia: Davis, 1977:189-204.

${ }^{4}$ Hachinski VC, Iliff L. Duboulay GH, et al. Cerebral blood flow in dementia. Arch Neurol 1975;32:632-7.

s Abbruzzese M, Favale E, Leandri M, Ratto S. Spinal components of the cerebral somatosensory evoked response in normal man: the "S wave". Acta Neurol Scand 1978;58:213-20.

- Abbruzzese G. Cocito L. Ratto S. Abbruzzese M, Leandri $M$. Favale E. A reassessment of sensory evoked potential parameters in multiple sclerosis: a discriminant analysis approach. J Neurol Neurosurg Psychiatry' 1981;44:133-9.

${ }^{7}$ Winer BJ. Statistical Principles in Experimental Design New York: McGraw-Hill, 1971.

${ }^{*}$ Abbruzzese M, Favale E, Leandri M, Ratto S. Electrophysiological assessment of the central lemniscal pathway in man. Experientia 1979;35:775-6.
${ }^{9}$ Desmedt JE, Cheron G. Somatosensory evoked potentials to finger stimulation in healthy octogenarians and in young adults: wave forms, scalp topography and transit times of parietal and frontal components. Electroencephalogr Clin Neurophysiol 1980;50:404-25.

${ }^{10}$ Hume AL, Cant BR. Shaw NA, Cowan JC. Central somatosensory conduction time from 10 to 79 years. Electroencephalogr Clin Neurophysiol 1982:54:4954.

"Tomlinson BE. The pathology of dementia. In: Wells CE, ed. Dementia. Philadelphia: Davis, 1977: 113-53.

${ }^{12}$ Noel P, Desmedt JE. Cerebral and far-field somatosensory evoked potentials in neurological disorders involving the cervical spinal cord. brainstem, thalamus and cortex. In: Desmedt JE, ed. Clinical Uses of Cerebral, Brainstem and Spinal Somatosensory Evoked Potentials. Prog clin Neurophysiol. Basel: Karger, 1980; vol. 7:205-30.

13 Joiassen RC, Shagass C, Mancal EL, Roemer RA. Somatosensory evoked potentials in Huntington's disease. Electroencephalogr Clin Neurophysiol 1982;54:483-93.

${ }^{14}$ Fazio C. Vascular pathology of the spinal cord. In: Minkler J, ed. Pathology of the Nervous System. New York: McGraw-Hill, 1971;2:1548-67. 